\title{
Hyperthermia exposure induces apoptosis and inhibits proliferation in HCT116 cells by upregulating miR-34a and causing transcriptional activation of p53
}

\author{
ZAN LUO $^{1}$, KANGXIA ZHENG $^{1}$, QI FAN ${ }^{1}$, XINYAO JIANG $^{2}$ and DEHAI XIONG ${ }^{1}$ \\ Departments of ${ }^{1}$ Gastrointestinal Surgery and ${ }^{2}$ Anesthesiology, \\ Chongqing Three Gorges Central Hospital, Wanzhou, Chongqing 404000, P.R. China
}

Received February 26, 2017; Accepted August 4, 2017

DOI: $10.3892 /$ etm.2017.5257

\begin{abstract}
Hyperthermia, as an anticancer therapeutic strategy, presents notable advantages in conjunction with irradiation and/or chemotherapy in the treatment of cancer by promoting apoptosis and inhibiting proliferation. A number of studies have documented that hyperthermia inhibits cancer progression through transcriptional activation of $\mathrm{p} 53$, which promotes cell cycle arrest and apoptosis. However, the underlying molecular mechanisms of hyperthermia-regulated apoptosis and proliferation dependent on p53 remain largely unknown. To investigate the effects and molecular mechanism of hyperthermia on the apoptosis and proliferation of colorectal carcinoma (CRC) HCT116 cells, the present study assessed cell apoptosis and proliferation following exposure to hyperthermia $\left(42^{\circ} \mathrm{C}\right.$ for $\left.2-4 \mathrm{~h}\right)$. The results indicated that, compared with the control group at $0 \mathrm{~h}$, hyperthermia exposure for 2 and $4 \mathrm{~h}$ induced the apoptosis of HCT116 cells $(\mathrm{P}<0.05)$, inhibited cell proliferation by causing cell cycle arrest at G1/G0 phase $(\mathrm{P}<0.05)$, and significantly increased microRNA (miR)-34a expression $(\mathrm{P}<0.05)$, but not miR-34b, miR-34c, miR-215 and miR-504 expression. The transcriptional activity of p53 on its consensus sequence and downstream target genes, namely p21, B cell lymphoma 2-associated X protein, mouse double minute 2 homolog, p53 upregulated modulator of apoptosis and growth arrest and DNA-damage-inducible $45 \alpha$, was subsequently detected. The data indicated significantly higher transcriptional activity of p53 following hyperthermia exposure for 2 and $4 \mathrm{~h}(\mathrm{P}<0.05)$, and these observations were similar to the effects of transfection with miR-34a mimics in HCT116 cells. Furthermore, transfection with miR-34a antagomiR supressed hyperthermia-induced apoptosis and promoted
\end{abstract}

Correspondence to: Professor Dehai Xiong, Department of Gastrointestinal Surgery, Chongqing Three Gorges Central Hospital, 165 Xincheng Road, Wanzhou, Chongqing 404000, P.R. China E-mail: 1208505185@qq.com

Key words: colorectal cancer, hyperthermia, p53, microRNA-34a, apoptosis, proliferation cell cycle progression following hyperthermia exposure when compared with transfection controls $(\mathrm{P}<0.05)$. Collectively, these findings indicate that miR-34a may serve an important role in hyperthermia-regulated apoptosis and proliferation in HCT116 cells by influencing the transcriptional activity of p53.

\section{Introduction}

Colorectal cancer (CRC) is the second leading cause of cancer-related mortality in Asia, and is classified as a terminal illness due to its relatively high rates of chemoresistance and hepatic metastasis (1). To overcome these problems, novel strategies in addition to primary treatments for colorectal cancer have been investigated (2). At present, primary treatment for CRC involves complete surgical removal of the primary tumor and regional lymph nodes (3). The prognosis of patients with CRC is dependent on tumor stage and grade; however, as resection is typically performed in late stage CRC for $30-40 \%$ of cases, the prognosis is generally poor (4).

Hyperthermia exposure above temperatures that are physiologically optimal affects numerous biological processes in cells and tissues, including proliferation, migration, invasion and apoptosis, by modifying the physical properties of cellular components to induce negative cellular responses (5). Hyperthermia is typically studied in combination with chemotherapy drugs. Fałkowska-Podstawka and Wernicki (6) have reported that hyperthermia exposure denatures proteins and induces DNA and RNA damage, which interrupts vital cellular processes and promotes apoptosis. Kim et al (7) identified a potential mechanism of apoptotic induction following hyperthermia exposure that involved activation of tumor necrosis factor-related apoptosis-inducing ligand. Additionally, Kalamida et al (8) reported that hyperthermia not only potently induced apoptosis by activating caspase-9, but also exerted a universal suppressive effect on cancer cell proliferation and reversed chemoresistance caused by chemoagent treatment. The potential mechanisms regarding inhibited proliferation are considered to involve the suppression of tumor cell replication and metabolism. For instance, in the renal cell carcinoma (RCC) cell line 786-O, hyperthermia exposure suppressed Ku80 expression and lead to G2/M phase cell cycle arrest, which may represent a 
potential mechanism of hyperthermia-mediated suppression of proliferation (9).

The cellular response to hyperthermia has been widely studied, though the role of microRNA (miRNA/miR) in hyperthermia remains largely unknown. A number of miRNAs have been demonstrated to be thermally responsive $(10,11)$. Due to the numerous functions of miRNAs, studies into the miRNA profile associated with hyperthermia are necessary. Notably, hyperthermic miRNAs may be mediators of some of the biological and/or therapeutic properties of hyperthermia (12).

The gene for p53 (TP53) is mutated in 50\% of human cancers, including CRC (13). p53 is among the most well-established cancer inhibitors, and regulates cell cycle arrest, DNA repair and apoptosis (14). The effect of hyperthermia on p53 expression indicates an involvement of p53 in hyperthermic inhibition of tumor growth (15). Furthermore, hyperthermia exposure activated p53 and caused the activation of cell cycle checkpoints (16). They also reported that, in human liver carcinoma HepG2 cells expressing wild type p53, hyperthermia caused DNA damage response-induced G2/M arrest through activated p53 and ATM/ATR, which was followed by apoptosis, while this was not observed in Huh7 cells expressing mutant p53 (16). These results indicate a critical role of p53 in the cellular effects of hyperthermia.

Multiple miRNAs, including miR-215, miR-504, and miR-34a, b and c, may be transcriptionally activated by p53 (17). Furthermore, the miR-34a has also been reported to serve a critical regulatory role in the posttranscriptional functions of p53 (18). Thus, it may be hypothesized that feedback regulation exists between miR-34 and $\mathrm{p} 53$.

In the present study, it was determined whether hyperthermia could induce apoptosis and cell cycle arrest in the CRC cell line HCT116, and the involvement of p53 was investigated. The potential regulatory effects of microRNA-34a in the p53-dependent hyperthermic response were also assessed.

\section{Materials and methods}

Cell culture and treatment. Human colorectal cancer HCT116 and TP53-/- HCT116 cells (HCT116 ${ }^{\text {TP53-/- }) ~ c e l l s ~ w e r e ~ p u r c h a s e d ~}$ from the American Type Culture Collection (Manassas, VA, USA). The cells were maintained in Dulbecco's modified Eagle's medium (Thermo Fisher Scientific, Inc., Waltham, MA, USA), supplemented with $10 \%$ heat-inactivated fetal bovine serum (FBS, Gibco; Thermo Fisher Scientific, Inc.) at $37^{\circ} \mathrm{C}$ and $5 \% \mathrm{CO}_{2}$. The medium was replenished every 3 days and when the cells reached $80-90 \%$ confluence, they were suspended with $0.25 \%$ trypsin (Gibco; Thermo Scientific, Inc.) and used in experiments.

In a hyperthermia exposure group (HYP), 5x10 $/$ well HCT116 cells seeded in 12-well plates were incubated in DMEM medium supplemented with 10\% FBS (Gibco; Thermo Fisher Scientific, Inc.) in an incubator (Forma Series II 3110; Thermo Fisher Scientific, Inc.) preheated to $42^{\circ} \mathrm{C}$ for 0,2 and 4 h. Additionally, a HYP group of HCT116 ${ }^{\text {TP53-- }}$ cells was subjected to hyperthermia for $2 \mathrm{~h}$. Control groups (CTL) of each cell line were incubated at $37^{\circ} \mathrm{C}$ for the same time periods. Following hyperthermia exposure, the cells were incubated at $37^{\circ} \mathrm{C}$ for the indicated time periods (2 and $4 \mathrm{~h}$ ) prior to analysis.

Transfection with microRNA mimics. Oligofectamine reagent (Thermo Fisher Scientific, Inc.), miR-34a (cat. no. C-300551-07; GE Healthcare Dharmacon, Inc., Lafayette, CO, USA), b (Assay ID, PM10743; cat. no. AM17100) and c (Assay ID, AM12342; cat. no. AM17000), scrambled mimics (cat. no. 4464058), and antago-scrambled (cat. no. 4464076) and antago-miR-34a miRNAs (Assay ID, MH11030; cat. no. 4464084) (all Thermo Fisher Scientific, Inc.) were employed following the manufacturer's protocol. To detect the effect of miR-34a, b or $c$ on the transcriptional activity of p53, miR-34a, b or c, or negative control scrambled mimics were transfected into HCT116 cells. To detect the effects of miR-34a on apoptosis and cell cycle distribution, antago-miR-34a or antago-scrambled miRNAs were transfected into HCT116 cells. Briefly, 5x10 5 cells/well were plated in a 6-well plate (Corning Incorporate, Corning, NY, USA) for $16 \mathrm{~h}$. A total of $200 \mathrm{nM}$ microRNA mimics was transfected transiently into cells. Flow cytometry and luciferase reporter assay experiments were performed $24 \mathrm{~h}$ after transfection. Western blotting and reverse transcription-quantitative polymerase chain reaction (RT-qPCR) analysis were performed $48 \mathrm{~h}$ after transfection.

Annexin V-fluorescein isothiocyanate (FITC)/propidium iodide (PI) double staining and flow cytometry analysis. The HCT116 cells were subjected to hyperthermia or normothermia as above for 0-4 h. Subsequently, an annexin V-FITC/PI double staining assay was performed according to the manufacturer's protocol of an Annexin V-FITC/PI apoptosis detection kit (Thermo Fisher Scientific, Inc.). In brief, $\sim 5 \times 10^{5}$ cells were harvested, washed with chilled PBS and resuspended in binding buffer containing $5 \mu \mathrm{l}$ Annexin V-FITC for $10 \mathrm{~min}$ in the dark at room temperature, after which the binding buffer was removed by centrifugation at $1,000 \mathrm{x} \mathrm{g}$ at $4^{\circ} \mathrm{C}$ for $10 \mathrm{~min}$. The cells were then resuspended in reaction buffer containing $5 \mu \mathrm{l} \mathrm{PI}$, and flow cytometry analysis was immediately performed to detect apoptosis using a three laser Navios flow cytometer (Beckman Coulter, Inc., Brea, CA, USA) according the manufacturer's protocol and FlowJo software (version 7.6.3; FlowJo LLC, Ashland, OR, USA) software.

Cell cycle analysis. The cells $\left(1 \times 10^{6}\right)$ were washed with ice-cold PBS, collected and fixed in $70 \%$ ice-cold ethanol overnight at $4^{\circ} \mathrm{C}$ and incubated with with $5 \mu \mathrm{g} / \mathrm{ml}$ PI Sigma-Aldrich; Merck $\mathrm{KGaA}$, Darmstadt, Germany) at $37^{\circ} \mathrm{C}$ for $10 \mathrm{~min}$, subsequently cell cycle analyses were performed using a three laser Navios flow cytometer according the manufacturer's protocol and FlowJo software (version 7.6.3). The proportion of cells in $\mathrm{G} 0 / \mathrm{G} 1, \mathrm{~S}$, and $\mathrm{G} 2 / \mathrm{M}$ phases was measured.

Luciferase reporter assays. A pGL3 firefly luciferase reporter plasmid containing the p53 consensus binding sequence (pGL3-P53BS, 5'-TACAGAACATGTCTAAGCATGCTG GGGACT-3' 30 mer) (19). A control pGL3-basic vector and a Renilla luciferase internal control plasmid, pRL-SV40, were purchased from Promega Corporation (Madison, WI, USA). A total of $1 \times 10^{5}$ cells in each group were cultured in 24-well plates in DMEM containing $10 \% \mathrm{FBS}$ at $37^{\circ} \mathrm{C}$ overnight. The 
cells were cotransfected with pRL-SV40 and pGL3-P53BS or pGL3-basic using Lipofectamine ${ }^{\circledR} 2000$ (Thermo Fisher Scientific, Inc.), according to the manufacturer's protocol. The cells were harvested 24 and $48 \mathrm{~h}$ after transfection and cell lysates were analysed for firefly and renilla luciferase activity using a Dual-Luciferase ${ }^{\circledR}$ Reporter Assay System (Promega Corporation), according to the manufacturer's protocol, and a microplate reader (Synergy 2 Multi-Mode Microplate Reader; BioTek Instruments, Inc., Winooski, VT, USA). Data were presented as a fold induction in luciferase activity compared with the pGL3-basic vector. Three independent transfection experiments were performed in triplicate for each experimental construct.

Western blot analysis. Cells were subjected to hyperthermia or normothermia as above. The cells were then harvested, washed twice with $1 \mathrm{ml}$ chilled PBS, and lysed with total protein lysis buffer (Guangzhou RiboBio Co., Ltd., Guangzhou, China). Total protein $(50 \mu \mathrm{g})$ measured by bicinchoninic acid assay kit (Sigma-Aldrich; Merck KGaA) was mixed with $10 \mu 15 \mathrm{X}$ SDS loading buffer and incubated for $10 \mathrm{~min}$ at $100^{\circ} \mathrm{C}$, and then $50 \mu \mathrm{g}$ total protein was separated by $12 \%$ SDS-PAGE and transferred to polyvinylidene fluoride (PVDF) membranes. After transferring, 5\% bovine serum albumin (Sigma-Aldrich; Merck KGaA) in PBS was employed as a blocking solution to block unspecific sites on the PVDF membranes at room temperature for $30 \mathrm{~min}$. Western blotting was performed with anti- $\beta$-actin antibody at 1:5,000 dilution (cat. no. mAbcam 8226; Abcam, Cambridge, UK), anti-pro caspase 3 antibody at 1:1,000 dilution (cat. no. ab32150; Abcam) and anti-active caspase 3 antibody at 1:1,000 dilution (cat. no. ab32042; Abcam) at room temperature for $2 \mathrm{~h}$. A horseradish peroxidase-conjugated anti-rabbit immunoglobulin $\mathrm{G}$ antibody at 1:5,000 dilution (cat. no. ab6721; Abcam) was used as the secondary antibody at room temperature for $1 \mathrm{~h}$. $\beta$-actin was used as the internal reference. Protein signals were detected using enhanced chemiluminescence reagents (Thermo Fisher Scientific, Inc.).

RT-qPCR analysis. Total RNA was extracted from the HCT116 and HCT116 ${ }^{\text {TP53-- }}$ cells exposed to hyperthermia or normothermia for $2 \mathrm{~h}$ using TRIzol reagent (Thermo Fisher Scientific, Inc.), according to the manual. Following RNA isolation, the concentration of purified RNA was determined with a UV spectrophotometer (Thermo Fisher Scientific, Inc.). cDNA was reverse transcribed from the extracted total RNA using a Reverse Transcriptase kit (Guangzhou RiboBio Co., Ltd.). To analyse miRNA levels, RT was performed with specific miRNA stem-loop primers for miR-34a (assay ID, 478047_mir), miR-34b (assay ID, 478050_mir), miR-34c (assay ID, 478052_mir), miR-215 (assay ID, 478516_mir) and miR-504 (assay ID, 478956_mir) (all Thermo Fisher Scientific, Inc.). The PCR was performed using Taqman ${ }^{\circledR}$ Universal PCR Master mix kit (Thermo Fisher Scientific, Inc.) and the ABI7500 system (Applied Biosystems; Thermo Fisher Scientific, Inc.) under the following conditions: $95^{\circ} \mathrm{C}$ for $10 \mathrm{~min}$, then 60 cycles of $95^{\circ} \mathrm{C}$ for $15 \mathrm{sec}$ and $60^{\circ} \mathrm{C}$ for $1 \mathrm{~min}$. The levels of miRNA were measured using the primer-probes from the Taqman microRNA Assay system (cat. no. A25576; Applied Biosystems; Thermo Fisher Scientific, Inc.) according to the manufacturer's protocol. U6 small nuclear RNA (Assay ID, 001973; cat. no. 4427975; Thermo Fisher Scientific, Inc.), provided by the Taqman microRNA Assay system, was used for normalization.

To analyze mRNA levels, a SYBR-Green Master Mix (Thermo Fisher Scientific, Inc.) was used in the ABI7500 system under the following conditions: $95^{\circ} \mathrm{C}$ for $10 \mathrm{~min}$, then 60 cycles of $95^{\circ} \mathrm{C}$ for $15 \mathrm{sec}$ and $60^{\circ} \mathrm{C}$ for $1 \mathrm{~min}$ The specific primers used were as follows: For Forlow, forward, 5'-CAT GTACGTTGCTATCCAGGC-3' and reverse, 5'-CTCCTT AATGTCACGCACGAT-3'; for p21, forward, 5'-TGTCCG TCAGAACCCATGC-3' and reverse, 5'-AAAGTCGAAGTT CCATCGCTC-3'; for B cell lymphoma 2-associated X protein (BAX), forward, 5'-CCCGAGAGGTCTTTTTCCGAG-3' and reverse, 5'-CCAGCCCATGATGGTTCTGAT-3'; for mouse double minute 2 homolog (MDM2), forward, 5'-ACG ACAAAGAAAACGCCACA-3' and reverse, 5'-CTCTCC CCTGCCTGATACAC-3'; for p53 upregulated modulator of apoptosis (PUMA), forward, 5'-GCCAGATTTGTGAGA CAAGAGG-3' and reverse, 5'-CAGGCACCTAATTGGGCT C-3'; and for growth arrest and DNA-damage-inducible $45 \alpha$ (GADD45A), forward, 5'-GAGAGCAGA AGACCGAAA GGA-3' and reverse, 5'-CACAACACCACGTTATCGGG-3'. $\beta$-actin mRNA expression was used to normalize the mRNA levels. All data was calculated using the comparative threshold cycle $\left(2^{-\Delta \Delta \mathrm{Cq}}\right)$ method (20).

Statistical analysis. All data were analyzed for statistical significance using SPSS 13.0 software (SPSS, Inc., Chicago, IL, USA). Data were expressed as the mean \pm standard deviation from at least 3 independent experiments performed in duplicate. Statistical comparisons of the results were performed using one-way analysis of variance followed by a Tukey's post hoc test. $\mathrm{P}<0.05$ was considered to indicate statistical significance.

\section{Results}

Effects of hyperthermia on cell cycling and apoptosis in HCT116 cells. To assess whether hyperthermia induced cell cycle arrest and apoptosis in HCT116 cells, the cells were maintained at $37^{\circ} \mathrm{C}$ (CTL group) or $42^{\circ} \mathrm{C}$ (HYP group) for three time intervals $(0,2$ and $4 \mathrm{~h})$, respectively. The cells were then analyzed by flow cytometry to determine the rate of apoptosis and percentages of different cell phases. As depicted in Fig. 1A and B, no significant change in the rate of cell apoptosis was observed in the CTL group following incubation at $37^{\circ} \mathrm{C}$ for the different time intervals. By contrast, the percentages of apoptotic cells in the HYP group significantly increased following incubation at $42^{\circ} \mathrm{C}$ for 2 and $4 \mathrm{~h}(\mathrm{P}<0.05$ vs. $0 \mathrm{~h}$ HYP group; Fig. $1 \mathrm{~A}$ and B). To verify that this elevation in apoptosis was caused by hyperthermia exposure, the levels of cleaved caspase-3 were assessed by western blotting. As depicted in Fig. 1C, it was observed that hyperthermia exposure increased the levels of cleaved caspase-3 over time. Additionally, the results of cell cycle analysis demonstrated that the percentages of G1/G0-phase cells in the HYP group significantly increased, while those of G2/M-phase cells significantly decreased, following hyperthermia exposure for 2 and $4 \mathrm{~h}(\mathrm{P}<0.05$; Fig. 1D). These results demonstrated that 
A
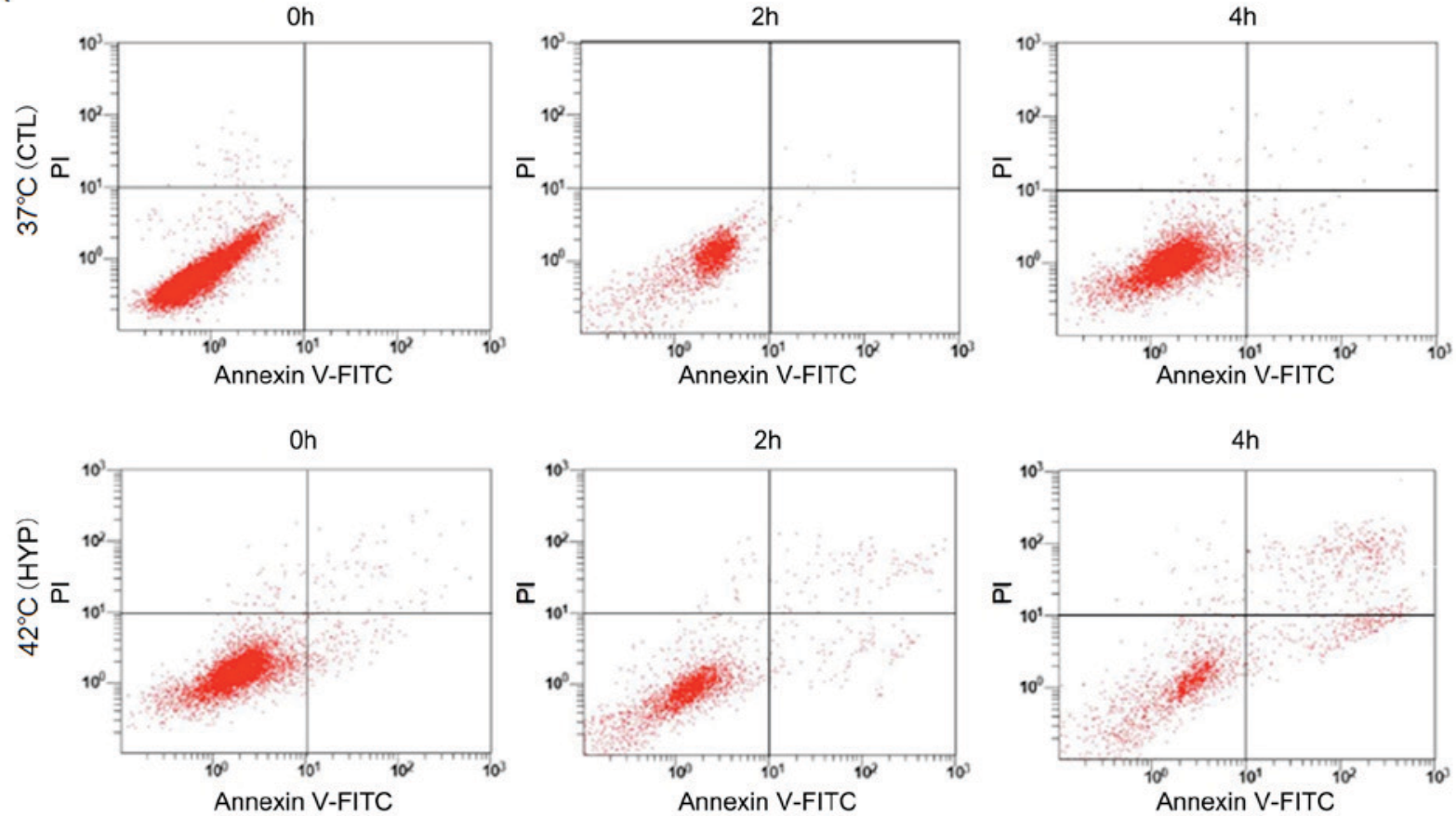

B

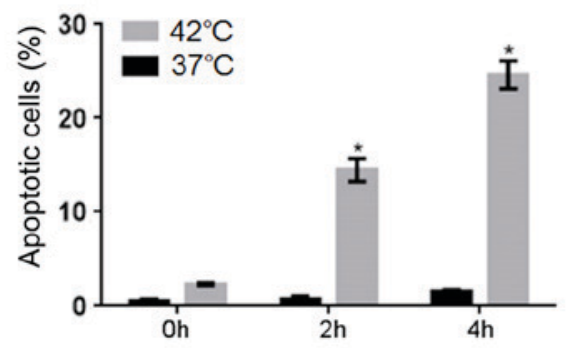

C

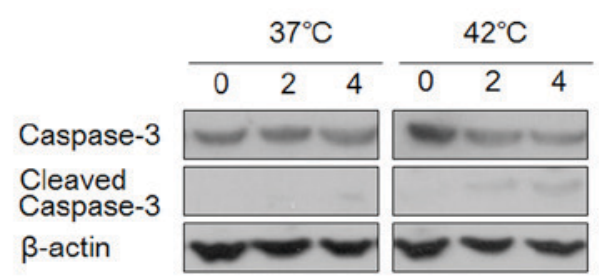

D

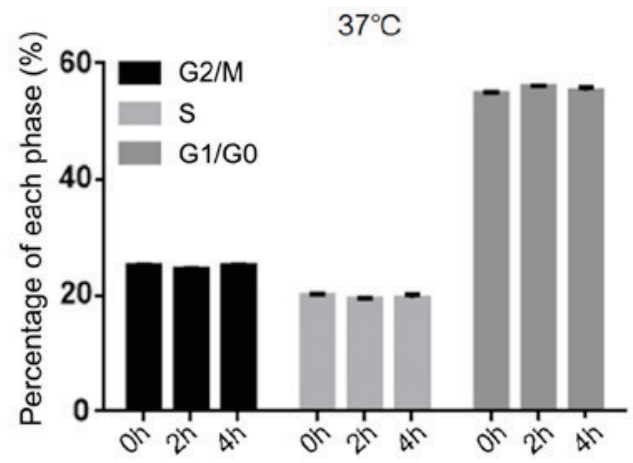

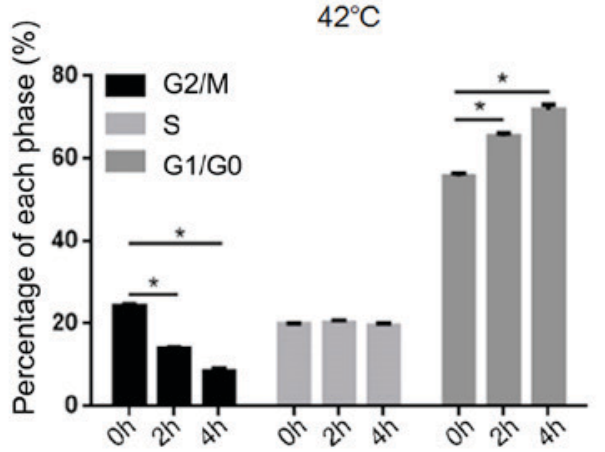

Figure 1. Hyperthermia exposure promotes apoptosis and induces cell cycle arrest in HCT116 cells. (A) Detection of apoptosis following hyperthermia exposure by Annexin V-FITC/PI staining and flow cytometry analysis. (B) Percentages of apoptotic cells. (C) Western blot analysis of active caspase-3 in hyperthermia-exposed cells. (D) Cell cycle analysis by PI staining followed by flow cytometry. * $<<0.05$ vs. 0 h HYP group. HYP, hyperthermia; CTL, control; FITC, fluorescein isothiocyanate; PI, propidium iodide.

hyperthermia significantly induced apoptosis and cell cycle arrest in the HCT116 cells.

Hyperthermia exposure upregulates miR-34a and activates p53 transcriptional activity. To investigate whether hyperthermia could affect the expression of microRNAs potentially involved in a p53-miRNA feedback loop, the HCT116 cells incubated at 37 or $42^{\circ} \mathrm{C}$ for $2 \mathrm{~h}$ were subjected to RT-qPCR to evaluate the expression of miR-34a, miR-34b, miR-34c, miR-215 and miR-504. The results of RT-qPCR indicated that the levels of miR-34b, miR-34c, miR-215 and miR-504 did not differ significantly in the CTL or HYP groups over the $4 \mathrm{~h}$ incubation period (data not shown). By contrast, significant upregulation of miR-34a was identified in the HYP group after 2 and $4 \mathrm{~h}$ of hyperthermia $(\mathrm{P}<0.05$; Fig. 2). Notably, compared with the CTL group, the expression of miR-34a was 
miR-34a

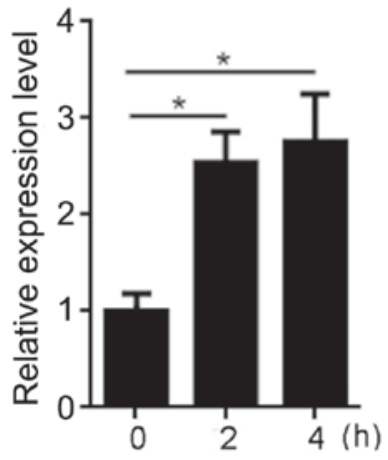

miR-215

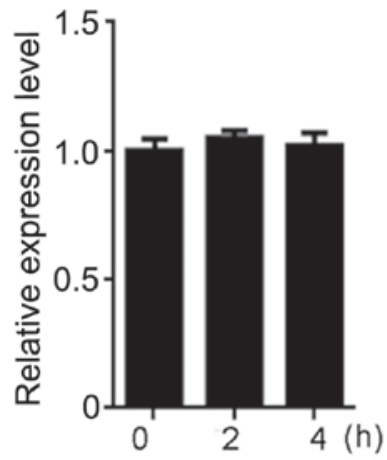

miR-34b

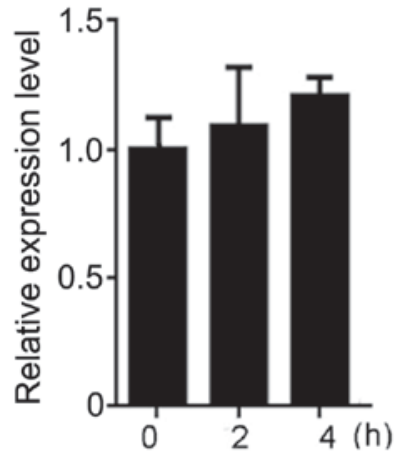

miR-504

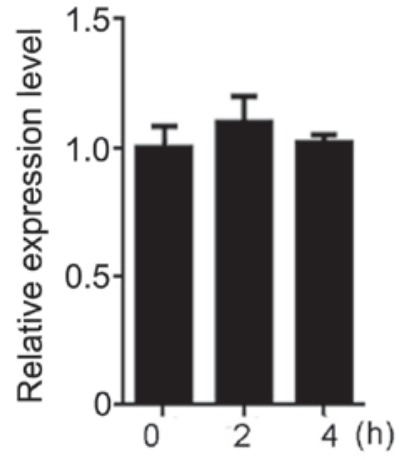

miR-34c

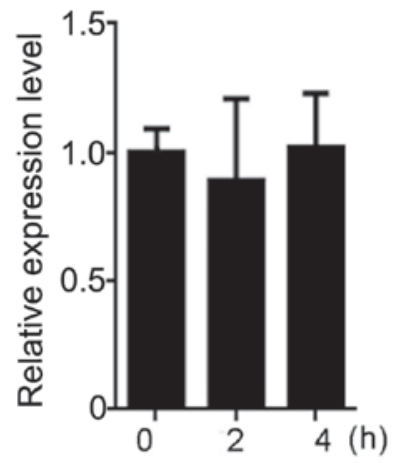

Figure 2. miR-34a upregulates following hyperthermia exposure in HCT116 cells. The expression levels of miR-34a, miR-34b, miR-34c, miR-215 and miR-504 in HCT116 cells were measured by reverse transcription-quantitative polymerase chain reaction following cell incubation at 37 or $42^{\circ} \mathrm{C}$. ${ }^{*} \mathrm{P}<0.05$. miR, microRNA.

increased by 2.5 or 2.9 fold after hyperthermia exposure for 2 or $4 \mathrm{~h}$, respectively, suggesting that miR-34a expression was increased by hyperthermia.

To assess the effects of the hyperthermia-induced miR-34a upregulation on p53 expression, RT-qPCR was performed to evaluate the effect of miR-34a overexpression on the downstream target genes transcriptionally activated by $\mathrm{p} 53$, including p21, BAX, MDM2, PUMA and GADD45A (21). Compared with the CTL group, hyperthermia exposure for $2 \mathrm{~h}$ significantly promoted the expression of miR-34a $(\mathrm{P}<0.05)$, and as expected, this upregulation in miR-34a caused significant increases in the expression of all target genes assessed $(\mathrm{P}<0.05$; Fig. 3A). To determine whether this increased gene expression was dependent on the presence of the p53 protein, the PCR assay was repeated in HCT116 ${ }^{\text {TP53-- }}$ cells following hyperthermia exposure. Similar to the HCT116 cells, the HCT116 ${ }^{\text {TP53-l- }}$ cells exhibited a significant upregulation in miR-34a following hypothermia exposure $(\mathrm{P}<0.05)$. However, hyperthermia exposure failed to affect the expression of p21, BAX, MDM2 and GADD45A in the HCT116 ${ }^{\text {TP53-- }}$ cells (Fig. 3B). Interestingly, upregulated PUMA mRNA was still observed in the HCT116 ${ }^{\mathrm{TP} 53-/-}$ cells, as in the HCT116 cells, following hypothermia exposure $(\mathrm{P}<0.05)$. Luciferase reporter assays were subsequently performed in the HCT116 cells to assess whether hyperthermia-induced miR-34a expression enhanced the promoter activity of the p53 consensus binding sequence within a pGL3-P53BS vector. As depicted in Fig. 3C, hyperthermia exposure increased luciferase activity compared with CTL group over time ( $<<0.05$ vs. 0 h HYP).
The transfection of miR-34a and miR-34b by 3.5 and 2.7 fold, respectively, significantly increased luciferase activity, which confirmed the induction of luciferase activity by overexpression of miR-34a and miR-34b (Fig. 3D, P<0.05 vs. Scrambled mimics). No significant difference was observed in luciferase activity following transfection with miR-34b or miR-34c mimics.

Hyperthermia promotes apoptosis partially through upregulating miR-34a in HCT116 cells. To determine whether hyperthermia induced apoptosis and cell cycle arrest in HCT116 cells by stimulating miR-34a expression, antago-miR-34a was transfected into HCT116 cells prior to hyperthermia exposure. At $24 \mathrm{~h}$ posttransfection, the cells were exposed to hyperthermia. The results indicated that, in the HCT116 cells, the introduction of antago-miR-34a decreased the elevated rate of apoptosis induced by hyperthermia exposure after 2 and $4 \mathrm{~h}$, relative to the antago-scrambled group at the same time points $(\mathrm{P}<0.05$; Fig. 4A). Upon determining the effect on cell proliferation, as expected, the introduction of antago-miR-34a decreased the percentage of G1/G0-phase cells and increased the percentage of $\mathrm{G} 2 / \mathrm{M}$-phase cells following hyperthermia exposure for $4 \mathrm{~h}$ ( $\mathrm{P}<0.05$ vs. antago-scrambled group; Fig. 4B).

Collectively, the present results indicate that hyperthermia exposure enhances apoptosis and cell cycle arrest at least in part through the upregulation of miR-34a, which may thus activate the transcriptional activity of p53 in HCT116 cells; however, the exact mechanisms underlying the upregulation of miR-34a remain to be elucidated. 
A miR-34a

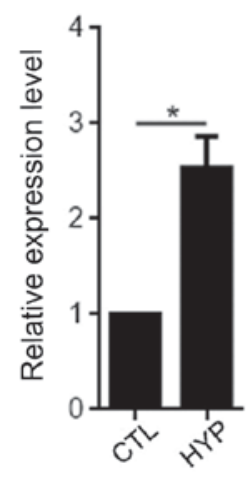

B

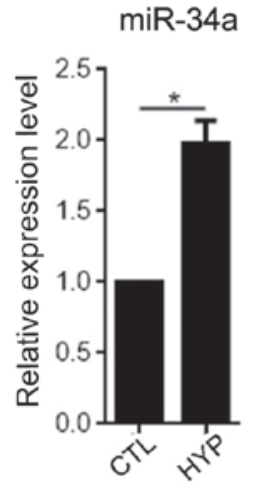

C

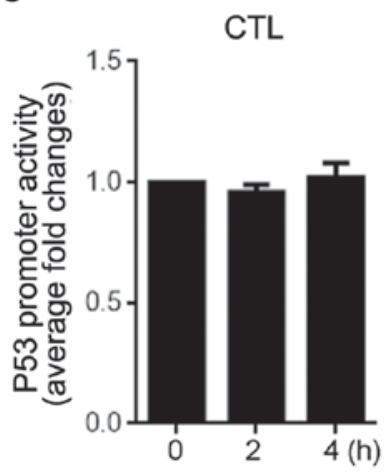

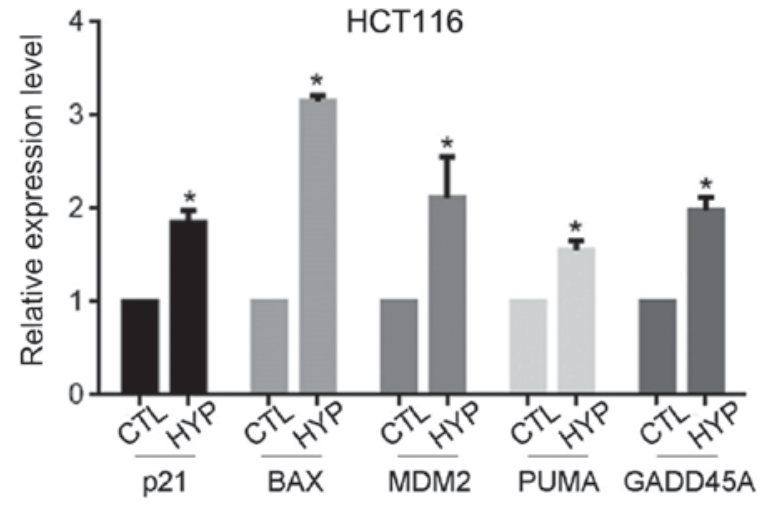

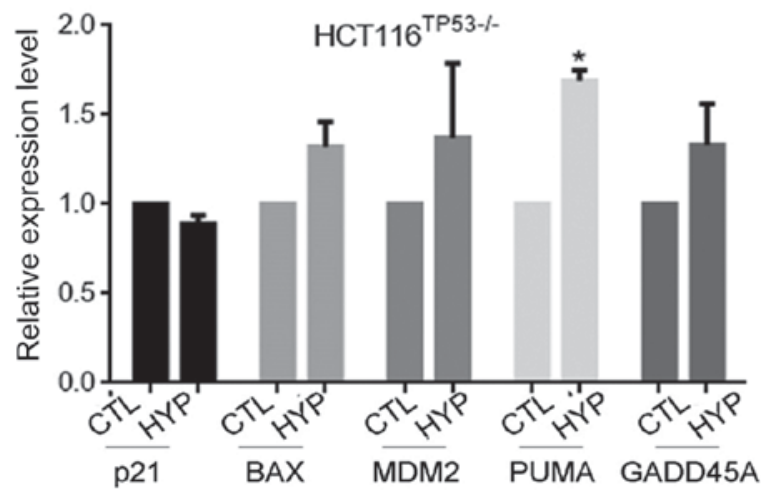

D

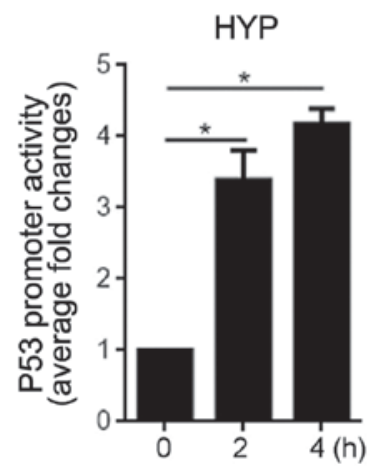

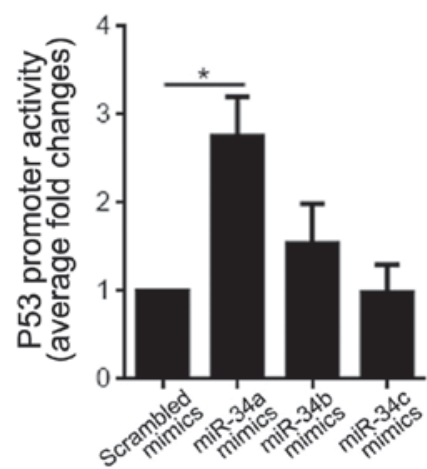

Figure 3. Hyperthermia-induced miR-34a expression increases p53 transcriptional activity. Reverse transcription-quantitative polymerase chain reaction was performed to measure the expression of miR-34a, p21, BAX, MDM2, PUMA and GADD45A in (A) HCT116 and (B) HCT116 ${ }^{\text {TP53-- }}$ cells following hyperthermia exposure. (C) A luciferase reporter assay was performed to assess the transcriptional activity of p53 following hyperthermia exposure. (D) Detection of p53 transcriptional activity following miR-34a transfection. "P<0.05. miR, microRNA; BAX, B cell lymphoma 2-associated X protein; MDM2, mouse double minute 2 homolog; PUMA, p53 upregulated modulator of apoptosis; growth arrest and DNA-damage-inducible 45 $\alpha$; HYP, hyperthermia; CTL, control.

\section{Discussion}

In addition to surgery, chemotherapy, radiation and biological therapy, hyperthermia has become a leading strategy for the treatment of cancer, and is a key part of multidisciplinary therapy (9). In RCC, hyperthermia is accepted as an alternative method to surgery in certain patients who are not suitable as surgical candidates (22). In CRC, hyperthermia is also used as an alternative method in selected patients (23). However, hyperthermia presents a variable success as an anti-cancer therapy in CRC. While neoplastic cells exhibit relatively higher sensitivity to hyperthermia than normal cells, multiple factors cause the variable outcomes due to the cancer cells also exhibiting differential degrees of sensitivity to hyperthermia (24,25). Bordonaro et al (23) reported that, in CRC, the mutation status of Kirsten rat sarcoma viral oncogene homolog (KRAS) determined cell sensitivity to hyperthermia, as cells lacking functional KRAS exhibited sustained hyperactivation of extracellular signal-regulated kinase signaling and increased Wingless/integrated-t-catenin signaling. It has also been observed that mutations in TP53 increase the resistance of cancer cells to hyperthermia by inactivating the 
A

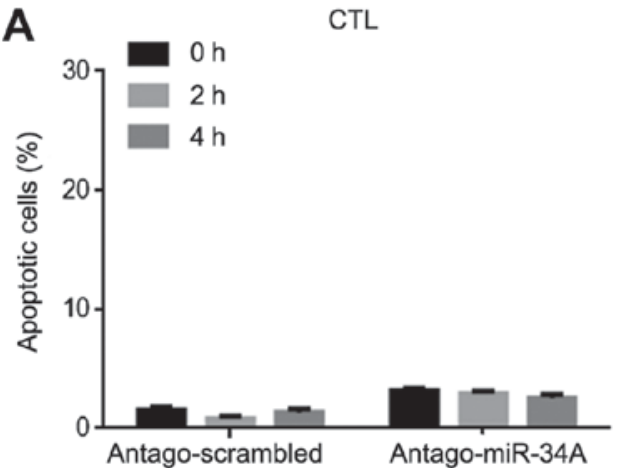

B

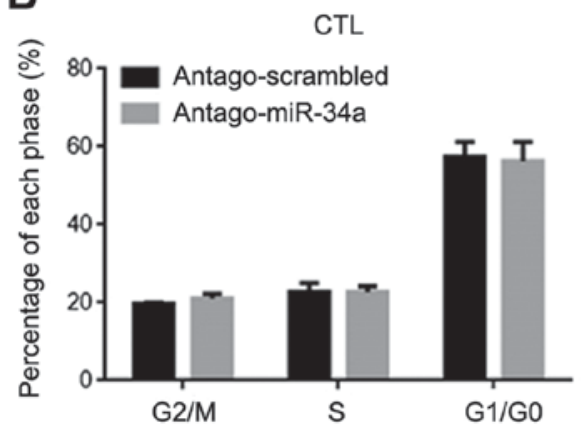

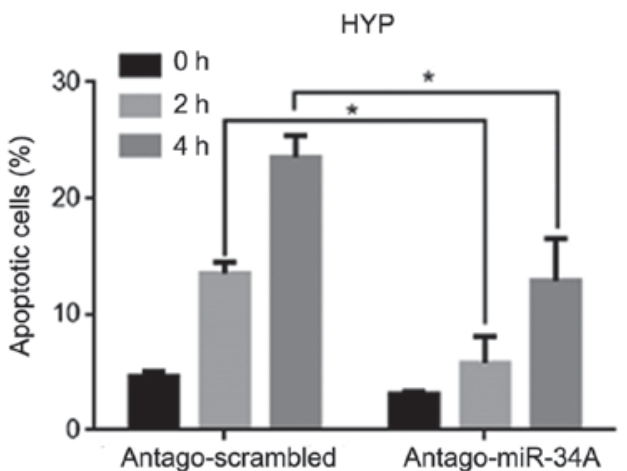

HYP

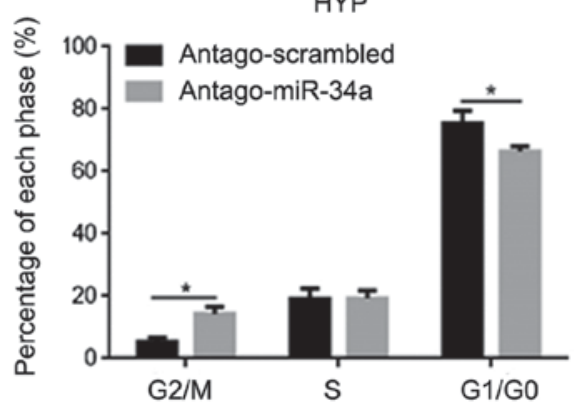

Figure 4. miR-34a regulates apoptosis and cell cycle arrest in hyperthermia-exposed HCT116 cells. (A) Antago-miR-34a decreased the elevated rate of apoptosis induced by hyperthermia exposure after 2 and $4 \mathrm{~h}$ in HCT116 cells. (B) Antago-miR-34a promoted cell cycle progression from G1 phase following hyperthermia exposure. ${ }^{*} \mathrm{P}<0.05$. miR, microRNA; HYP, hypothermia; CTL, control.

downstream regulated genes of p53 $(26,27)$. Therefore, understanding the mechanisms of hyperthermia-induced apoptosis and cell cycle arrest in CRC cells may elucidate methods of promoting the sensitivity of CRC to hyperthermia.

p53 is a transcription factor that modulates the expression of numerous downstream target genes responsible for directly and/or indirectly controlling apoptosis, cell cycle arrest, senescence, DNA repair and genetic stability in response to various cellular stresses (28), including hyperthermia (29). It has been reported that hyperthermia exposure promotes apoptosis depending on the activation status of p53 (26). This indicates an association of hyperthermia-induced apoptosis and cell cycle arrest with the downstream gene targets of p53, which serve critical roles in cell cycle arrest (p21, GADD45A), apoptotic cell death (PUMA, BAX), and p53 feedback regulation (MDM2) (21).

In the present study, hyperthermia increased the expression of miR-34a, but not of its family members miR-34b and miR-34c. It is established that miR-34a serves anti-proliferative and apoptotic roles by contributing to p53 function, principally through targeting multiple inhibitors of p53, including proteins that deacetylate p53 (sirtuin 1, metastasis associated 1 family member $2 /$ histone deacetylase 1) (30-33) and the negative transcriptional modulator MDM4 (34). The present data demonstrated that miR-34a expression was induced by hyperthermia exposure independently of p53, thus indicating a link in a p53 feedback loop. The results also suggested that upregulated miR-34a expression following hyperthermia exposure may have increased the sensitivity of the HCT116 cells to hyperthermia treatment. Surprisingly, overexpression of miR-34a in HCT116 cells slightly increased apoptotic sub-population, indicates the potential pro-apoptotic role of miR-34a. Notably, the G1/G0 phase arrest caused by hyperthermia exposure or the introduction of miR-34a indicated a potential mechanism by which hyperthermia induced apoptosis and inhibited proliferation.

In conclusion, the present data demonstrate for the first time that hyperthermia may upregulate the expression of miR-34a which may thus cause the transcriptional activation of p53 to induce apoptosis and cell cycle arrest in G1/G0 phase in HCT116 cells. These results provide novel insight into hyperthermia cytotoxicity, and may indicate therapeutic targets regarding hyperthermia sensitivity in CRC.

\section{Acknowledgements}

The present study was supported by the Scientific and Technical Supporting Project of Wanzhou District, Chongqing (grant no. 201403007).

\section{References}

1. Jemal A, Bray F, Center MM, Ferlay J, Ward E and Forman D: Global cancer statistics. CA Cancer J Clin 61: 69-90, 2011.

2. Winawer SJ, Zauber AG, O'Brien MJ, Ho MN, Gottlieb L, Sternberg SS, Waye JD, Bond J, Schapiro M, Stewart ET, et al: Randomized comparison of surveillance intervals after colonoscopic removal of newly diagnosed adenomatous polyps. The National Polyp Study Workgroup. N Engl J Med 328: 901-906, 1993.

3. Kornmann M, Formentini A, Ette C, Henne-Bruns D, Kron M, Sander S, Baumann W, Kreuser ED, Staib L and Link KH: Prognostic factors influencing the survival of patients with colon cancer receiving adjuvant 5-FU treatment. Eur J Surg Oncol 34: 1316-1221, 2008. 
4. Zlobec I and Lugli A: Prognostic and predictive factors in colorectal cancer. J Clin Pathol 61: 561-569, 2008.

5. Oei AL, Vriend LE, Crezee J, Franken NA and Krawczyk PM: Effects of hyperthermia on DNA repair pathways: One treatment to inhibit them all. Radiat Oncol 10: 165, 2015.

6. Fałkowska-Podstawka $M$ and Wernicki A: Heat shock proteins in health and disease. Pol J Vet Sci 6: 61-70, 2003.

7. Kim SY, Lee DH, Song X, Bartlett DL, Kwon YT and Lee YJ: Role of Bcl-xL/Beclin-1 in synergistic apoptotic effects of secretory TRAIL-armed adenovirus in combination with mitomycin $C$ and hyperthermia on colon cancer cells. Apoptosis 19: $1603-1615,2014$.

8. Kalamida D, Karagounis IV, Mitrakas A, Kalamida S, Giatromanolaki A and Koukourakis MI: Fever-range hyperthermia vs. Hypothermia effect on cancer cell viability, proliferation and HSP90 expression. PLoS One 10: e0116021, 2015.

9. Qi D, Hu Y, Li J, Peng T, Su J, He Y and Ji W: Hyperthermia induces apoptosis of 786-O cells through suppressing Ku80 expression. PLoS One 10: e0122977, 2015.

10. Wilmink GJ, Roth CL, Ibey BL, Ketchum N, Bernhard J, Cerna CZ and Roach WP: Identification of microRNAs associated with hyperthermia-induced cellular stress response. Cell Stress Chaperones 15: 1027-1038, 2010.

11. Yu J, Liu F, Yin P, Zhu X, Cheng G, Wang N, Lu A, Luan W, Zhang N, Li J, et al: Integrating miRNA and mRNA expression profiles in response to heat stress-induced injury in rat small intestine. Funct Integr Genomics 11: 203-213, 2011.

12. Oshlag JZ, Devasthanam AS and Tomasi TB: Mild hyperthermia enhances the expression and induces oscillations in the Dicer protein. Int J Hyperthermia 29: 51-61, 2013

13. Olivier M, Eeles R, Hollstein M, Khan MA, Harris CC and Hainaut P: The IARC TP53 database: New online mutation analysis and recommendations to users. Hum Mutat 19: 607-614, 2002.

14. Efeyan A and Serrano M: p53: Guardian of the genome and policeman of the oncogenes. Cell Cycle 6: 1006-1010, 2007.

15. Graeber TG, Osmanian C, Jacks T, Housman DE, Koch CJ, Lowe SW and Giaccia AJ: Hypoxia-mediated selection of cells with diminished apoptotic potential in solid tumours. Nature 379: 88-91, 1996.

16. Ren YL, Yu JH and Kinghorn AD: Development of anticancer agents from Plant-derived Sesquiterpene lactones. Curr Med Chem 23: 2397-2420, 2016.

17. Navarro F and Lieberman J: miR-34 and p53: New insights into a complex functional relationship. PLoS One 10: e0132767, 2015.

18. Yamakuchi M, Ferlito M and Lowenstein CJ: miR-34a repression of SIRT1 regulates apoptosis. Proc Natl Acad Sci USA 105: 13421-13426, 2008

19. el-Deiry WS, Tokino T, Velculescu VE, Levy DB, Parsons R, Trent JM, Lin D, Mercer WE, Kinzler KW and Vogelstein B: WAF1, a potential mediator of p53 tumor suppression. Cell 75: 817-825, 1993.

20. Livak KJ and Schmittgen TD: Analysis of relative gene expression data using real-time quantitative PCR and the 2(-Delta Delta C(T)) method. Methods 25: 402-408, 2001
21. Sullivan KD, Gallant-Behm CL, Henry RE, Fraikin JL and Espinosa JM: The p53 circuit board. Biochim Biophys Acta 1825: 229-244, 2012.

22. Campbell SC, Novick AC, Belldegrun A, Blute ML, Chow GK, Derweesh IH, Faraday MM, Kaouk JH, Leveillee RJ, Matin SF, et al: Guide lines for management of the clinical T1 renal mass. J Urol 182: 1271-1279, 2009.

23. Bordonaro M, Shirasawa S and Lazarova DL: In Hyperthermia Increased ERK and WNT signaling suppress colorectal cancer cell growth. Cancer (Basel) 8: pii:E49, 2016.

24. Hobohm U, Stanford JL and Grange JM: Pathogen-associated molecular pattern in cancer immunotherapy. Crit Rev Immunol 28: 95-107, 2008.

25. Trieb K, Sztankay A, Amberger A, Lechner $\mathrm{H}$ and Grubeck-Loebenstein B: Hyperthermia inhibits proliferation and stimulates the expression of differentiation markers in cultured thyroid carcinoma cells. Cancer Lett 87: 65-71, 1994.

26. Guan J, Stavridi E, Leeper DB and Iliakis G: Effects of hyperthermia on $\mathrm{p} 53$ protein expression and activity. J Cell Physiol 190 365-374, 2002

27. Okamoto K, Shinoura N, Egawa N, Asai A, Kirino T, Shibasaki F and Shitara N: Adenovirus-mediated transfer of p53 augments hyperthermia-induced apoptosis in U251 glioma cells. Int J Radiat Oncol Biol Phys 50: 525-531, 2001

28. Li T, Kon N, Jiang L, Tan M, Ludwig T, Zhao Y, Baer R and $\mathrm{Gu}$ W: Tumor suppression in the absence of p53-mediated cell cycle arrest, apoptosis, and senescence. Cell 149: 1269-1283, 2012.

29. Gu ZT, Wang H, Li L, Liu YS, Deng XB, Huo SF, Yuan FF, Liu ZF, Tong HS and Su L: Heat stress induces apoptosis through transcription-independent p53-mediated mitochondrial pathways in human umbilical vein endothelial cell. Sci Rep 4: 4469, 2014.

30. Juan LJ, Shia WJ, Chen MH, Yang WM, Seto E, Lin YS and Wu CW: Histone deacetylases specifically down-regulate p53-dependent gene activation. J Biol Chem 275: 20436-20443, 2000.

31. Luo J, Nikolaev AY, Imai S, Chen D, Su F, Shiloh A, Guarente L and Gu W: Negative control of p53 by Sir2alpha promotes cell survival under stress. Cell 107: 137-148, 2001.

32. Luo J, Su F, Chen D, Shiloh A and Gu W: Deacetylation of p53 modulates its effect on cell growth and apoptosis. Nature 408: 377-381, 2000

33. Vaziri H, Dessain SK, Ng Eaton E, Imai SI, Frye RA, Pandita TK, Guarente L and Weinberg RA: hSIR2(SIRT1) functions as an NAD-dependent p53 deacetylase. Cell 107: 149-159, 2001.

34. Finch RA, Donoviel DB, Potter D, Shi M, Fan A, Freed DD, Wang CY, Zambrowicz BP, Ramirez-Solis R, Sands AT and Zhang N: Mdmx is a negative regulator of p53 activity in vivo. Cancer Res 62: 3221-3225, 2002. 